\title{
Erratum to: AANS/CNS Section on Tumors
}

\section{0th Anniversary special issue}

\author{
Anthony L. D'Ambrosio • Fred G. Barker II
}

Published online: 30 September 2014

(C) Springer Science+Business Media New York 2014

Erratum to: J Neurooncol (2014) 119:449-450

DOI 10.1007/s11060-014-1590-3

The first author's name was incomplete in the original publication. It is correct in this erratum.

The online version of the original article can be found under doi:10.1007/s11060-014-1590-3.

A. L. D’Ambrosio ( $\square)$

Neurosurgeons of New Jersey, 1200 East Ridgewood Avenue,

Ridgewood, NJ 07450, USA

e-mail: dambrosio@neurosurgerynj.com

F. G. Barker II

Neurosurgical Service, Massachusetts General Hospital, Boston,

MA, USA

e-mail: barker@helix.mgh.harvard.edu

F. G. Barker II

Department of Surgery (Neurosurgery), Harvard Medical

School, Boston, MA, USA 